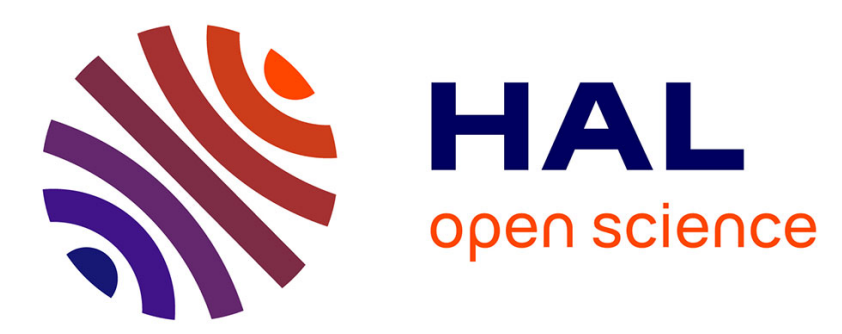

\title{
Fort impact du dépistage généralisé du VIH par TROD par une infirmière dédiée au sein d'un service d'urgences en Amazonie française
}

V. Morel, A Lucarelli, A Gaudinot, L Adriouch, E Gaubert-Maréchal, P. Abboud, Félix Djossou, P. Couppie, Mathieu Nacher, Loïc Epelboin

\section{To cite this version:}

V. Morel, A Lucarelli, A Gaudinot, L Adriouch, E Gaubert-Maréchal, et al.. Fort impact du dépistage généralisé du VIH par TROD par une infirmière dédiée au sein d'un service d'urgences en Amazonie française. 19 ème Journées Nationales d'Infectiologie (JNI), Jun 2018, Nantes, France. hal-02870301

\section{HAL Id: hal-02870301 https://hal.univ-guyane.fr/hal-02870301}

Submitted on 16 Jun 2020

HAL is a multi-disciplinary open access archive for the deposit and dissemination of scientific research documents, whether they are published or not. The documents may come from teaching and research institutions in France or abroad, or from public or private research centers.
L'archive ouverte pluridisciplinaire HAL, est destinée au dépôt et à la diffusion de documents scientifiques de niveau recherche, publiés ou non, émanant des établissements d'enseignement et de recherche français ou étrangers, des laboratoires publics ou privés. 
INF- 06

Nantes

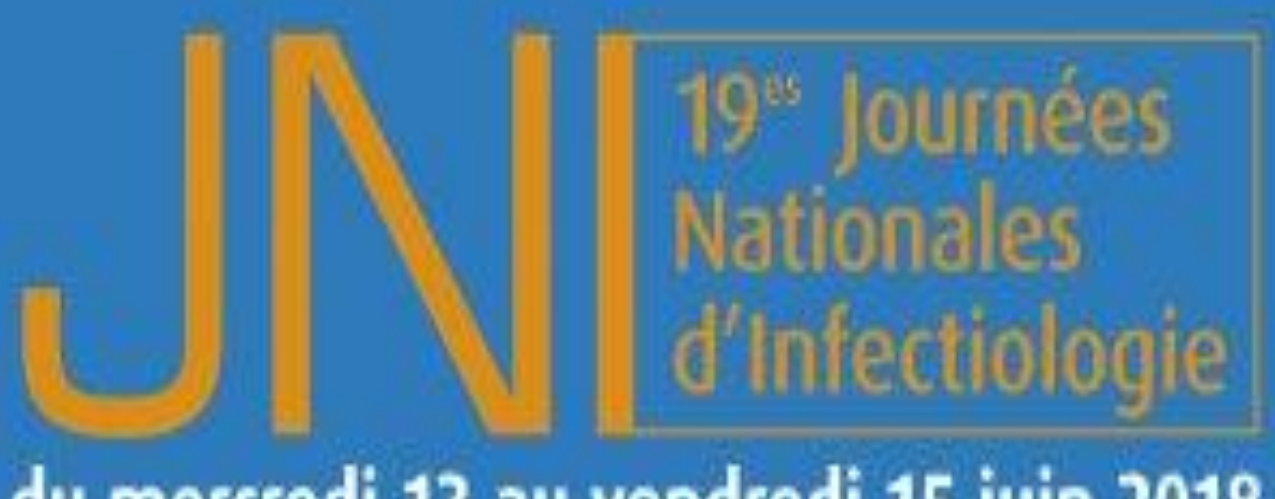

du mercredi 13 au vendredi 15 juin 2018 jeudi 1 j juin 2018

V. Morel , A. Lucarelli, A. Gaudinot, L. Adriouch, E. Gaubert-Maréchal, P.Abboud, F. Djossou, P. Couppié, M. Nacher, L. Epelboin.

Centre Hospitalier de Cayenne, Andrée ROSEMON.

\section{CONTEXTE}

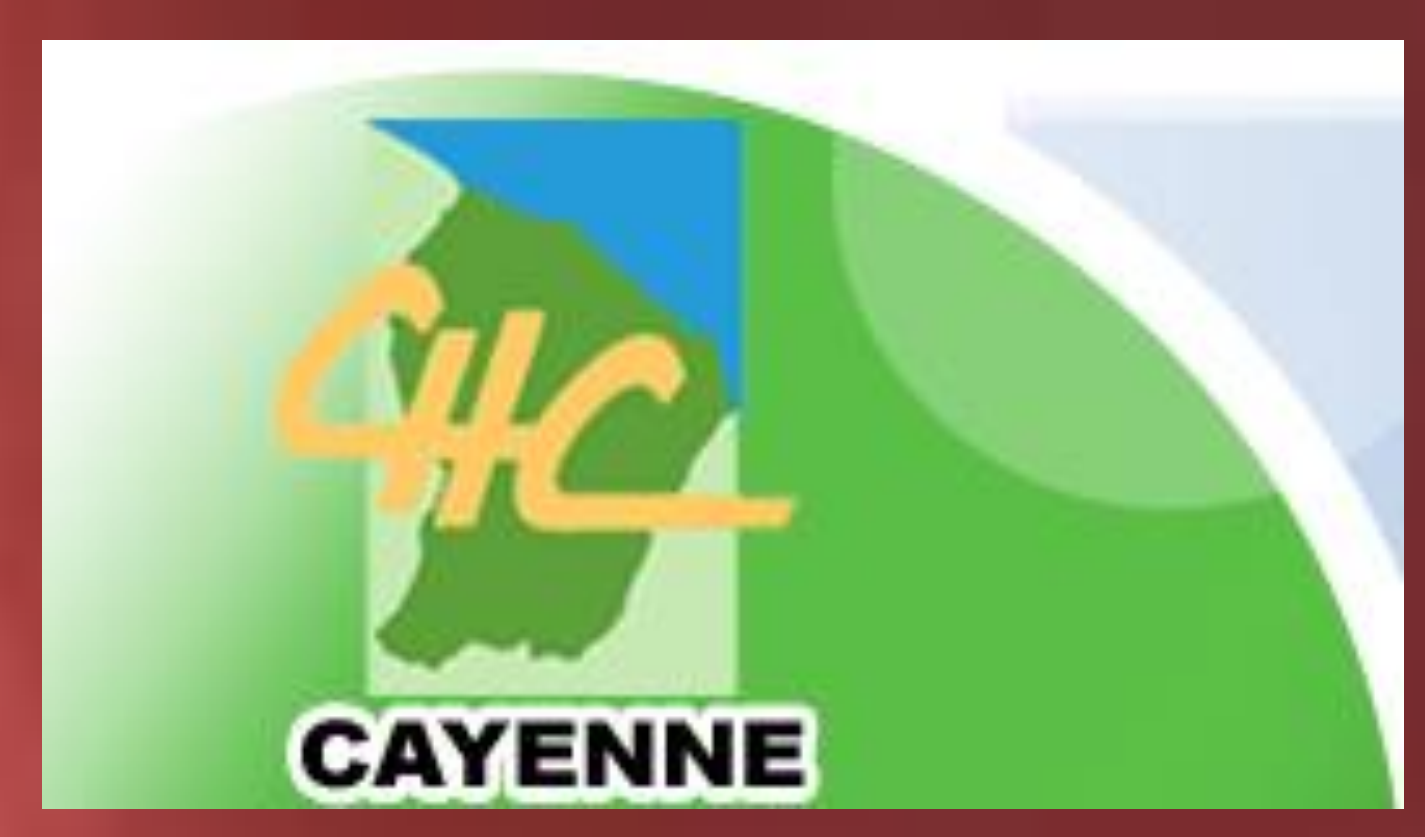

- Guyane: territoire français en Amérique du Sud avec la prévalence de l'infection par le VIH, $>1 \%$, la plus élevée de France.

- 500 à 600 personnes ignorant leur séropositivité sur 250000 habitants

- CH de Cayenne : infirmière mobile de dépistage (IMOD) en charge de l'activité de dépistage du VIH.

\section{MÉTHODES}

Déroulement du 01/01 au 31/12/2017 au Service d'accueil des Urgences du CHC Tout patient de 18 à 70 ans en capacité de répondre au questionnaire.

Critères d'exclusion: filières psychiatrique et judiciaire.

IMOD présente de $8 \mathrm{~h}$ à $14 \mathrm{~h}$ du lundi au vendredi à temps partiel 80\%: entretien + proposition de dépistage

\section{RESULTATS}

Sexe ratio $\mathrm{H} / \mathrm{F}=1,2$

80\% avaient fait un dépistage au cours de leur vie

64\% au cours des années

$36 \%$ au cours des douze derniers mois.

Motifs d'acceptation du TROD:

- $12 \%$ dans le cadre d'une prise de risque

- $\mathbf{5 1 \%}$ test de dépistage dans les 5 dernières années

- $\mathbf{3 7 \%}$ test $<1$ an.

CONCLUSION

\section{L
l']
de
pc}

